\title{
THE ORGANIZATIONAL TRANSFORMATION OF DOMINIQUE ANSEL (PASTRIES AND INNOVATION): ITS IMPLICATION TO EDUCATION AND BUSINESS
}

\author{
Rommel Pascual Manzon \\ International Maritime College of Oman (IMCO) Sohar, Sultanate of Oman
}

Article DOI: https://doi.org/10.36713/epra9408

DOI No: 10.36713/epra9408

\begin{abstract}
This paper discussed the organizational transformation of Dominique Ansel and its implication to education and business. It explains how the leadership of Ansel greatly affects the organization and transformed into a better situation.

KEYWORDS: organizational, transformation, leadership, education and business.
\end{abstract}

\section{INTRODUCTION}

I do not want my creation to kill my creativity, is a famous line delivered by Dominique Ansel during one of his interviews by Food Insider. The sensational Cronut he created in 2013 lifted him to the pedestal where his creativity in food, specifically pastry, did shine and recognized. His success has caught the attention of the people and gave them the urge to experience what the creations are. His business strategy is also a subject for inquiry to determine the measures he did to attain the success he have achieved.

Dominique Ansel boldly started his own bakery in 2011and presently have branches in the United States and in different countries. The worldwide attention and demand to his products have given him courage to expand and introduce his creativity in food to the different parts of the world. The attention from media and food adventurers gave him more room to show his artistic talent in the line of pastry making.

This paper is an analysis on Dominique Ansel and his business strategy. Who is Dominique Ansel? What business model is he applying and its implication? And What is his innovation to achieve success?

\section{PROFILE}

Dominique Ansel is a 43 years old young French-American pastry chef, businessman, leader and the creator of the Internet Sensation Cronut. He was born on 1978 at Beauvais, France. Ansel was the youngest of 4 siblings, raised and schooled in a Beauvais, a small city north of Paris. To help his family financially, he went to work as an apprentice at a local restaurant after high school at the age 16. He first worked in savory and then in pastry. He did his military service in French Guiana at the age 19 and as part of a community program teaching, he taught locals how to cook. After his military service, he moved to Paris to work in the kitchen of Patisserie Peltier then to the legendary bakery Fauchon a year later. He spent seven years in Fauchon and eventually took charge of Fauchon's International expansion helping set up shots in locations, such as Russia, Egypt, and Kuwait. (StarChefs 2012).

He migrated to the United States and worked as executive pastry chef at Daniel for six years. He was part of the team earned Daniel its first 4-star review from the New York Times, 3 Michelin stars and the James Beard's Outstanding Restaurant of the Year Award in 2010. In November 2011, he opened his own Bakery, Dominique Ansel Bakery, in SoHo Manhattan.

His invention of the Cronut in 2013 became a widely publicized phenomenon being named one of Time Magazine's best invention of the year. Ansel's Cronut became international sensation landing him on The Jimmy Fallon Show and Good Morning America and New York Times. Famous pastries he also created 
were the Frozen S'more, Hot Choc Message Bottle, Jasmine Flower Cookie shot and others.

A number of awards he received were: Best Pastry Chef in the U.S. by the James Beard Awards in 2012; Best New Bakery in 2012 by Time Out New York; Best Bakery of 2012 by Metromix; 1 Ordre du Merite Agricole Award; Most innovative people under 40 and 50 most influential French People in the World. At the age 39, he was the youngest and the first chef in America to be bestowed the honor World's Best Pastry Chef by the World's 50 Best Restaurants Award in 2017.

He opened branches at Hong Kong, the Dang Wen Li by Dominique Ansel; France-Paris, Tokyo, Japan and another in New York Flatiron neighborhood which is the Dominique Ansel Workshop, croissant shop. Aside from his shops, he also has videos at You Tube Channel, became judge in pastry competitions and his work has been featured in multiple cookbooks and magazines.

As the effect of the pandemic, Ansel was forced to close some of his stores located in Los Angeles and Tokyo but as a resilient businessman, he is planning to open new store in Las Vegas on 2022. Even during the pandemic, he has been active in the social media sharing recipes and activities to help people create their own food at home.

\section{ANALYSIS}

Dominique Ansel is undoubtedly the most celebrated and innovative pastry chef in the Western Hemisphere and for good reason. He combines magic, entertainment, craft, nostalgia, analogies, complexity, surprise, shapes, interesting presentations, contrasting textures and temperatures, and wow factor into his creations, as written by Michelle Greenwald in her feature Dominique Ansel Innovates.

He undoubtedly innovated the pastry industry, not just sticking to the basics but is obsessed in delivering the best possible product. Ansel values time with the right ingredients with the right temperature at the right time for his pastries which can be multisensory evoking when eaten. He uses quality and unique ingredients presenting difference flavors and appearance of a product in different time. Emotions are incorporated in his products evoking emotions and nostalgia to the customers.

$\mathrm{He}$ is known to use team approach in his leadership creating a collaborative environment that's busy but organized. He inspires his workers and made them execute his visons and learn his craft. He has a clear and consistent vision which the entire organization understand. $\mathrm{He}$ is known as nice, passionate, loyal, most humble and gives value to his employees. He believes in constant product iteration, to search ways to improve and make them more perfect. He subscribes to the notion, and works in a medium where the products can evolve on the fly and continuously moving, innovating, learning and growing. (Greenwald, 2015). Brainstorming is constantly done every 6-8 weeks for teams to come up with new ideas together. Regular tasting with feedbacks on menus as well as new menu ideas.

Benchmarking is also done outside the industry like nail art for ideas and inspiration. Not only do Ansel serve innovative pastries but add some magic and entertainment value. He values first his customers, to offer hospitality to go above and beyond self. He takes cares of his customers especially when they wait for long. Giving them gloves, hot chocolates during winter, or showing the activities in the kitchen to entertain.

There are also broadly inclusive indulgences. Ansel's goal is that his products be affordable to everyone compared to the meals he previously prepared at his previous work. He is also egalitarian that no matter their status, everyone has to wait in line. Dominique's employees are humble and helpful to customers. They are always pleasant, fun and informative.

He has brand equity extension, local market adaptation where he tailors his products on the local market where he put up his shop. Ansel embraces competition which gives his opportunity to innovate, encourage new concepts which makes customers more open in trying new things. He innovates his shop in a way that it will fit more people an support his concept, plays with color innovation and loves analogies and ingredient substitution.

Dominique incorporate ingredients in his dishes typically found in other parts of the word making it accessible to many. $\mathrm{He}$ is the always innovating to make customers' experience in his establishments special, memorable and wonderful.

Dominique Ansel utilizes different styles of leadership. Prominently, he is a transformational leader, organizational, agile and a $21^{\text {st }}$ century leader. He has a vision and leading his team beyond their selfinterest to innovate to transform for the best. He considers the moral and ethical values of the workers and the customers in his delivery of products. With his numerous branches and employees, he uses organizational leadership where he uses team approach, 
empowering and motivating the different groups to be able to carry out assignments and activities confidently.

The ability of the business to respond to the different demands of the customers and even the pandemic emulated/showed Ansel's Agile leadership style. Aside from team empowerment, he believes in customer satisfaction, superior quality product constantly innovating and improving, flexible to the different cultures of other countries as well as customer demands and maintaining uplifted team morale. Being a $21^{\text {st }}$ century leader, he uses his heart with multidimensional and integrative view. He has good relationship with his team/employees using open door policy in communication. Activities were done to maintain team work and uplifting morales. He is said to be kind, passionate and humble. Even in his products, he infuses emotions evoking also the customers'.

\section{EDUCATION AND BUSINESS IMPLICATIONS}

Being a business icon and celebrated chef can be attributed to many factors surrounding Dominique Ansel. His ability to utilize what he has and what the "environment" offers have helped him go up the ladder of success.

1. Leadership- Dominique Ansel utilized different styles of leadership in different situations. His flexibility has helped him maintain his business, able to expand and retain them even his loyal employees. The ability to continuously run a business and expand is a sign of good leadership within the organization. His resiliency during the pandemic would help further his business to thrive.

2. Human resource- Being a kind, humble, using open door policy to his employees. Using flexible leadership styles to fit his employees have good effect on his relationship and handling of his members. This would maintain a high morale creating cooperation and good working relationship. Working by example, making clear vision and making employees own the vision would maintain their loyalty and would function for a common goal for the company.

3. Customer- He makes sure that he puts the customers first in his business. His pastries and menus are made sure to be of best quality with constant innovation hence giving the best product to the customers. Services like store renovations for comfort, good customer services by the staff, making sure they are given comfort and entertainment while lining to buy and prices can be afforded by all walks of life.

4. Product- Famous pastries he created were the Cronut, Frozen S'more, Hot Choc Message Bottle, Jasmine Flower Cookie shot and others. With his high sense of creativity and innovation, his pastries and menus were constantly improved for the best. He utilized methods like benchmarking, competition, experimenting, learning and research to produce a quality product which can be patronized by many customers.

\section{CONCLUSION}

Dominique Ansel is a world renowned pastry chef and internet sensation because of his innovative culinary arts. With creativity and innovation, he has produced well patronized pastry products, have loyal customers, put up bakeries in different parts of the world and received numerous awards despite his young age. He used different styles of leadership like transformational, organizational, agile and $21^{\text {st }}$ century in manning his business which has leveraged him financially increasing profit.

He handles human resources such that they have maintain loyalty, with good performance, and with good customer relations. With his high sense of creativity and innovation, using benchmarking, competition, experimenting he created excitement and sense of magic and excitement which have maintained loyal customers and have even attracted tourists from all over the world.

This paper is an analysis on Dominique Ansel and his business strategy. Who is Dominique Ansel? What leadership styles is he applying and their implication? And What is his innovation to achieve success?

\section{RECOMMENDATIONS}

Recommendation to Businessmen

In putting up a pastry bakery or any business, it is recommended that Dominique Ansel's use of different leadership styles/theories should be practiced to compliment different situations within an organization. This would mean a flexible management which can help in the success of operation. 


\section{Recommendation to Pastry Chefs}

Innovation is the key to success as shown by Ansel which should be patterned by aspiring pastry chefs. The good response of customers to Ansel's creation have given proof to this assumption hence pastry chef should innovate using experimentation, continuous learning, benchmarking and listening to customers and employees.

\section{Recommendations to customers}

Ansel is undoubtedly one of the best modern food innovators at this time hence food enthusiast should be open to new ideas and presentations to enjoy what he has to offer. Her, both the chef and the customer are inspired to present and receive.

\section{REFERENCES}

1. BalvenieUS. (2017, October 20). Raw craft with Anthony Bourdain- Episode Thirteen: Dominique Ansel. You Tube. https://us.thebalvenie.com

2. Food Insider. (2020, January 17 ). Why the Cronut is still New York City's most Legendary Dessert. You Tube. https://www.insider.com

3. Greenwald, M.,(2015). How the Wildly (Deservedly) Successful Dominique Ansel Innovate. Forbes.U.S.A. Retrieved from https://www.forbes.com

4. Culinary Agents.,(2020)., Dominique Ansel. Retrieved from https://journal.businesstoday.org

5. Masterclass, (2021)., Dominique Ansel's Baking Career Highlight. Master Class Stuff. Retrieved from https://www.masterclass.com

6. Natfluence. (2014). Dominique Ansel: Owner of Dominique Ansel Bakery. Retrieved from https://natfuence.com

7. Burke, I., (2018). 12 Bewildering dishes that prove pastry chef Dominique Ansel is Transforming our definition of dessert. Retrieved from https://www.insider.com

8. Luck, a., (2020). The Top 10 Treats to Try at Dominique Ansel Bakery Japan., (2016). Retrieved from https://.tokyoweekender.com. 